\title{
PRÁTICAS DE POLICIAMENTO DA LEITURA NA ESCOLA
}

\section{PRACTICES OF READING POLICING IN THE SCHOOL}

\author{
Carlos Borges Junior \\ Doutorando em Linguística Aplicada pela Universidade Federal de Santa Catarina \\ Professor da Universidade do Tocantins \\ E-mail: borges-junior@hotmail.com
}

\section{RESUMO}

Este artigo problematiza o trabalho que a Escola realiza com a leitura. Faz uma relação teóricodiscursiva do ensino de leitura associado a algumas concepções de linguagem que fundamentaram o ensino de língua portuguesa e que acabaram contribuindo para o policiamento das atividades de leitura em contexto escolar. $\mathrm{O}$ artigo discute brevemente como a Escola foi constituída enquanto instituição detentora do papel fiscalizador do conhecimento, passando a monitorar as práticas desenvolvidas em seus espaços de ensino, especificamente as de leitura. O estudo critica a concepção de leitura associada à perspectiva gramatical de ensino da língua em contraste com a perspectiva dialógica, elegendo esta como uma proposta favorável ao ensino de leitura na escola. Ao final, sugere-se o gênero debate como proposta para as aulas de leitura. $\mathrm{O}$ artigo se consolida como resultado de estudos e discussões teóricas realizadas sobre o assunto no curso de doutorado, tendo como referências autores como Foucambert (1994), Goulemot (2001), entre outros.

Palavras-chave: Leitura. Práticas de Policiamento. Escola.

\begin{abstract}
This article problematizes the work done by the schools related to reading activities. It is a discussion regarding the theoretical and discursive relationship of reading instruction associated with some language concepts that grounded the Portuguese's teaching that contributed to the policing of reading activities in school context. The article discusses briefly how the school was established as an institution that holds the oversight role of knowledge, and turned to be the monitor of practices developed in their teaching spaces, specifically the reading. The study criticizes the design of reading associated with grammatical perspective of language teaching in contrast to the dialogical perspective, choosing this last as a favorable proposal to reading instruction in school. At the end, it is suggested that gender could contribute to the debate as a proposal for the reading classes. The article is consolidated as a result of studies and theoretical discussions on the subject in post-graduate programs, specially at the doctorate level, including authors such as Foucambert (1994), Goulemot (2001), among others.
\end{abstract}

Key-words: Reading. Policing Practices. School. 


\section{INTRODUÇÃo}

O historicismo se contenta em estabelecer um nexo causal entre vários momentos da história. Mas nenhum fato, meramente por ser causa, é só por isso um fato histórico. Ele se transforma em fato histórico postumamente, graças a acontecimentos que podem estar dele separados por milênios. O historiador consciente disso renuncia desafiar entre os dedos os acontecimentos, como as contas de um rosário. Ele capta a configuração em que a própria época entrou em contato com uma época anterior, perfeitamente determinada. Com isso, ele funda um conceito do presente como um "agora" no qual se infiltraram estilhaços do messiânico. (WALTER BENJAMIN)

A intenção de citar Benjamim na epígrafe deste artigo pode ser explicada a partir de algumas relações: 1) compreender o trabalho com a leitura na escola não apenas a partir de um nexo causal entre os vários momentos históricos de ensino, mas de reflexões que apontam para como a própria organização da Escola se estruturou para policiar a leitura em seus espaços sociais; 2) relacionar algumas concepções de linguagem que contribuíram com a escola no sentido de fiscalizar e monitorar o ensino de leitura e, 3) refletir sobre como essas relações reverberam positiva e/ou negativamente no trabalho com a leitura na escola. Esta proposta será desenvolvida a partir de discussões bibliográficas que fundamentarão a organização do pensamento crítico para problematizar o ensino de leitura na escola, apontando para práticas de policiamento.

Um olhar histórico cujo objetivo seja identificar a origem da Escola Moderna ${ }^{1}$ irá registrar o momento em que essa instituição é oficializada ${ }^{2}$ pelo aparelho do Estado como sendo a empresa autorizada, logo organizada, para formar ${ }^{3}$ indivíduos na sociedade. Destarte, que a família, a igreja entre outros setores, também contribuem para a formação social do indivíduo, porém é ainda a escola a que mais goza do status desse agenciamento, justamente porque dela emanam outros tipos de "saberes", os científicos, por exemplo, que legitimam seu modo de produção, construção e avaliação do conhecimento produzido. Então, valendo-se desse capital simbólico, ideológico, regimental e social, a escola moderna institucionaliza o conhecimento e passa a controlar as políticas de ensino, promovendo os indivíduos em níveis seriados de aprendizagem.

Esse contexto, aliado a um marco histórico que outorgou e convencionalizou poder à escola, possibilita que ela fiscalize, regulamente e promova os estudantes em relação ao nível de aprendizado conquistado por eles nas suas dependências de ensino. Por outro lado, quando um indivíduo consegue alcançar uma formação fora dos muros da escola, ou quando determinada criança recebe uma formação quanto à leitura das primeiras letras e já chega à escola lendo e escrevendo, por exemplo, ainda é essa instituição que recebe incumbência de classificar o sujeito segundo seus critérios de aprendizagem. Assim, consolida-se socialmente o papel conferido à Escola para que ela realize suas atividades de forma soberana sem que, durante muito tempo, tenha sido questionada em suas decisões. 
Para compreender o que a escola vem fazendo com a leitura, convém retomar algumas concepções de linguagem que deixaram marcas profundas tanto para o ensino de língua quanto de leitura. Nesse sentido, convém destacar 1) a concepção de língua(gem) enquanto um conjunto de normas e regras pautadas na gramática normativa e, associado a ela, 2) a compreensão de que o texto é um objeto a ser analisado enquanto estrutura, definido em tipologias textuais, cujas abordagens não extrapolam a forma, a estrutura, e 3), a perspectiva de que a linguagem estabelece relações entre os discursos sociais e individuais, por isso, dialógicos entre os sujeitos que enunciam e interagem durante $\mathrm{o}$ ato de ler.

Por muito tempo o trabalho com a leitura ${ }^{4}$ na escola esteve submetido a um modelo tradicional de ensino que pautava suas atividades a partir de orientações postuladas pela gramática normativa. A linguagem era vista como um conjunto de regras a serem rigorosamente seguidas. Essa perspectiva também orientou as atividades de produção de textos a partir das tipologias textuais que prescreviam definições, sistemas e estruturas fixas para organizar os discursos. As tipologias eram ensinadas como sistemas textuais homogêneos, conceitualmente, definidos, fechados, estáveis e estabilizados - ora denominados como textos narrativos, descritivos, dissertativos, etc. Consequente a essa concepção, quaisquer atividades desenvolvidas na escola passava pelo crivo estruturalista de classificação e, com a leitura, não foi diferente: lia-se para identificar, classificar, encontrar nos textos o que melhor preenchia as lacunas; reproduziam-se as mesmas palavras do texto como forma de provar que o havia entendido e assim por diante. Embora a escola, às vezes, ainda possua algumas atividades e ranços ligados a uma perspectiva tradicional de ensino e concepção de leitura, a discussão adotada para este artigo inscreve ao termo a ideia de que:

Ler é dar um sentido de conjunto, uma globalização e uma articulação dos sentidos produzidos pelas sequências. Não é encontrar o sentido desejado pelo autor, o que implicaria que o prazer do texto se originasse na coincidência entre o sentido desejado e o sentido percebido, em um outro tipo de acordo cultural, como algumas vezes pretendeu, em uma ótica na qual o positivismo e o elitismo não escaparão a ninguém. Ler é, portanto, construir e não reconstruir um sentido. A leitura é uma revelação pontual de uma polissemia do texto literário. A situação da leitura é, em decorrência disso, a revelação de uma das virtualidades significantes do texto. No limite, ela é aquilo pelo qual se atualiza uma de suas virtualidades, uma situação de comunicação particular, pois aberta. Se admitirmos, como o faço, que um texto literário é polissêmico, a análise do leitor parecerá, portanto pertinente, porque constitui um dos termos essenciais do processo de aprovação e de troca que é a leitura (GOULEMOT, 2001, p. 108).

Muitas vezes contrária a abordagem de Goulemot, a escola esteve empenhada em fiscalizar o que deveria, de fato, ser lido nos textos. Qualquer desvio do roteiro previamente orientado pela leitura oficial; que serviria de resposta ao professor e também aos alunos e que muitas vezes já vinha registrada nos livros didáticos - deveria ser considerada fora do padrão, logo, entendida como improcedente, incorreta. 
Este artigo quer olhar e problematizar a leitura na escola a partir desses contextos. Como destacado a priori tanto na epígrafe benjaminiana como no primeiro objetivo deste artigo, não interessa apenas um nexo causal entre os vários momentos da história com o ensino de leitura, mas uma perspectiva reflexiva com a qual se possa compreender de que forma a própria organização da escola faz com que essa atividade seja policiada no ambiente de ensino. Após essa relação, convém discutir como as atividades de leitura podem ser redimensionadas na escola para atingir outros espaços sociais de uso da linguagem.

\section{A PERSPECTIVA TRADICIONAL E O MONITORAMENTO DA LEITURA}

Quando se aciona a perspectiva tradicional ${ }^{5}$ da escola tem-se como pressuposto a razão de um ensino alicerçado por abordagens que se firmam e autoafirmam sob uma concepção de língua pautada na norma, logo, na regra, cuja abordagem gramatical é supervalorizada. Nessa concepção, o argumento de que ensinar e aprender língua(gem), cuja atividade de leitura se associa a ela, deve pôr em relação valorativa os princípios daquilo que o vernáculo gramatical rege como corretos e dignos de serem conhecidos pelos estudantes em formação. Por isso, os textos selecionados para ler na escola, no passado (e ainda no presente), passavam apenas pelo crivo da boa linguagem, logo somente os textos e escritores clássicos eram selecionados como fonte de leitura.

Por muito tempo a escola tradicional associou que saber-ler ${ }^{6}$ implicava "atribuir significado ao escrito, transformando-o em oral" (FOUCAMBERT, 1994, p. 3). Embora Foucambert (1994) se refira a uma perspectiva psicolingüística da década de 1960 ao falar sobre decifração, por muito tempo a escola tradicional entendeu que ler era decodificar e/ou decifrar o código. A relação que se estabelecia estava na ordem de que "saber-ler" significava "saber-decifrar". Tal relação concebia a leitura como um ato mecânico de verbalização do código escrito - uma visão estreita de um processo de construção de significados. Na escola, segundo Foucambert, "a leitura é presa de um corpo, apesar das nuanças, fundamentalmente homogêneo, que combina os pressupostos históricos da decifração com a descrição rigorosa das correspondências entre o oral e o escrito" (1994, p. 4).

O que vale ser colocado em evidência na citação do autor em relação à perspectiva de ensino tradicional da escola recai sobre a razão rigorosa da correspondência entre o oral e o escrito. Historicamente, as atividades escolares, na maioria das vezes, elegeram - ora ainda elegem - a escrita como o grande objetivo a ser alcançado. Daí que todas as propostas sempre esta- 
vam a ela associadas, de modo que a oralidade ou era a simples representação verbalizada do escrito (atividade prestigiada), ou apenas o comentário informal, por isso, desqualificado e deslegitimado pela escola.

Em A sombra do caos, Britto (1997) destaca como o ensino de língua se constituiu associado à tradição gramatical ${ }^{7}$. A partir da discussão proposta pelo autor, torna-se evidente apontar que a escola se instituiu também por conta de uma sistematização do ensino e, no que concerne ao estudo da língua, valeu-se de um aparato prescritivo para regular e avaliar o indivíduo quanto aos conhecimentos alcançados intramuros da própria instituição. Nessa concepção, saber usar a língua implica em ter pleno conhecimento da gramática que a constitui e que dá origem aos textos a serem apreciados, lidos. Por isso também a valoração de alguns escritos e escritores em relação a outros. Afinal, a escola elege certos autores para incluí-los no currículo.

Atualmente, podemos apontar as consequências que essa perspectiva construiu, sobretudo, para a compreensão da leitura na escola: leitura decifração - leitura transposição do código escrito em oral; leitura enquanto sequenciação de palavras verbalizadas, que constituem períodos, formam frases, parágrafos e textos; leitura busca de informações ${ }^{8}$, já que a escola trabalha com o paradigma perguntas e respostas, leitura enquanto soma do sentido das sucessivas palavras que compõem os textos, leitura como sequência de ideias e somatória de argumentos entre outras, somente para citar alguns sentidos.

Com essa configuração montada, torna-se absolutamente fácil a ação da escola para policiar, medir e mensurar o nível de proficiência leitora dos estudantes. Se os dados podem ser encontrados na artificialidade do texto, digo, apenas em suas estruturas de sentido denotativo, é fácil diagnosticar quem sabe encontrar tais sentidos ou não: os que conseguem são julgados bons leitores e os que não alcançam essas informações nos textos são avaliados negativamente. Assim, é mais simples observar, medir e mensurar os que conseguem dar conta das atividades de leitura. Promovem-se os que se adaptam, ou então, retêm-se aqueles que não alcançam as metas e objetivos esperados. Esse é o legado, o amalgama que o modelo tradicional de ensino da leitura deixa exposto, de forma ainda latente, no contexto escolar.

Não convém observar essa herança apenas com um olhar fatalista para concluir que a escola não tem jeito ou que as atividades de leituras estão fadadas ao fracasso, visto que a estrutura de ensino já está pré-configurada para se manter dentro da instituição escolar. Algumas escolas estão investindo em novas concepções de leitura. É necessário buscar outros caminhos, descobrindo veredas, rumos alternativos para fugir à formatação, bases e modelos préconcebidos pela escola. 


\section{A PERSPECTIVA DIALÓGICA PARA ENSINO DE LEITURA}

Uma saída possível para o ensino de leitura na escola está no pensamento dialógico. A concepção da formação de um sujeito crítico, que se constitui e se constrói no contínuo das práticas sociais, em contato com os diferentes mundos de significados que a leitura oferece pode ser alternativa em relação à perspectiva tradicional de trabalho. Nesta concepção, a atividade nunca é solitária, é constituída por alteridades, no plural. Assim, o sujeito se percebe individual e social, em um mundo cujo contexto se estabelece em relação a outros mundos, porque são muitos os modos de percepção do mesmo acontecimento, muitas as sensibilidades que permitem experimentar os "exercícios do ver" - valendo-se de uma metáfora de Martín-Barbero e Rey (2001).

A concepção de interação promove a construção de conhecimentos entre o eu e o outro e entre diversos discursos sociais. Nesse sentido, a escola pode mediar esse processo de formação do sujeito com as leituras de diferentes mundos, da "palavramundo", como assegura Paulo Freire (1981). Ao reconstruir os significados da leitura nas salas de aula, a escola contribuirá para uma formação de sujeitos que não se limitam apenas ao que está escrito nos textos, porém, que alcançam olhares mais profundos de uma sociedade a partir do que leu nos livros.

Logicamente, uma ação como esta não está circunscrita sob o estereótipo de uma visão estruturalista, conforme apregoam os fundamentalismos de um ensino tradicional alicerçado pelas vertentes gramaticais. Tem a ver com um ato crítico e político que encara o ensino e a leitura como processos de formação e constituição dos indivíduos em sujeitos de seu próprio discurso. Por isso, a função e o papel da escola podem e devem ser reconfigurados: abandona-se a perspectiva reguladora para se favorecer a mediação entre os diferentes conhecimentos a serem construídos.

Na situação de mediação, fazendo uma leitura benjaminiana do termo como processo, tendo por base o texto Caráter destrutivo ${ }^{9}$, no qual o autor destaca que o uso dos espaços anseiase aberto, sem que haja a necessidade de tomar o lugar de forma definitiva para fixar-se e impor os discursos aos outros, a mediação torna-se "o reconhecimento de como o mundo se simplifica enormemente quando posto à prova segundo mereça ser destruído ou não" (BENJAMIN, 2011, p. 224).

Talvez esteja aqui ante nós o momento histórico para se problematizar não só a leitura, mas o que ler ante a própria escola. De repente, é olhar para a instituição escolar erigida no tempo com as teorias que lhe estruturam e legitimam, mantendo-a no formato em que ela se nos apresenta e pôr em evidência se a imagem que nos chega deve ser destruída ou não. "Saber o que vai se encarregar de substituir a coisa destruída" e ocupar o lugar seria o "mais insignificante. 
Para começar no mínimo por um instante [talvez por um momento, diante e a partir de tantas teorias erigidas sobre a escola, permitir-se] o espaço vazio ${ }^{10}$, o lugar onde se achava o objeto, onde vivia a vítima" para se problematizar o que é a escola (BENJAMIN, 2011, p. 224). Não convém a definição, propõe-se um estudo de outros lugares a partir dos quais a escola seja um sinal, um ponto luminoso a emitir lampejos para que possa ser estudada como "um símbolo trigonométrico [que] está exposto ao vento, por todos os lados, ele está exposto ao palavratório, por todos os lados. Protegê-lo quanto a isso não faz sentido" (BENJAMIN, 2011, p. 224). A mediação torna-se a abertura para, o espaço vazio que, “com certeza haverá alguém que precise dele sem ocupá-lo", deixando-o sempre aberto ao outro, sempre dialógico (BENJAMIN, 2011, p. 224).

Há algo na interação, no dialogismo, que muito se relaciona ao caráter destrutivo. Segundo Benjamin, “o caráter destrutivo é o adversário do homem-estojo. O homem-estojo busca sua comodidade, e sua caixa é a síntese desta. O interior da caixa é o rastro revestido de veludo que ele imprimiu no mundo. O caráter destrutivo elimina até mesmo os vestígios da destruição" (BENJAMIN, 2011, p. 224).

A concepção de sujeito dialógico não se associa ao homem-estojo citado pelo autor, mas ao sujeito historicamente constituído, que tem consciência de suas ações no mundo. Parece valer-se do próprio caráter destrutivo para se conceber diante do mundo - a refazer-se continuamente. As atividades de leitura na escola devem atentar para essa formação de sujeitos: sujeitos conscientes de seus atos, por isso Sujeitos. Nesse sentido, faz-se necessário observar a instituição Escola a partir de um olhar que recupera as reminiscências do passado e projeta feixes de luz para compreender as instâncias do presente. Esse será o próximo tópico de discussão para refletir sobre a artificialização da leitura na escola e o quanto essa instituição se organiza para policiar essas atividades.

\section{RECONSTRUINDO O TRABALHO COM A LEITURA NA ESCOLA}

$\mathrm{Na}$ intenção de reconstruir o trabalho com a leitura na escola, faz-se necessário redimensionar a práxis do professor de língua. Nesse sentido, acredito que o professor de português poderia dar lugar ao professor de leitura. Esse seria um grande avanço para o ensino. O professor de leitura rompe, imediatamente, com o percurso histórico que focaliza a língua enquanto estrutura. Ele redimensiona a atenção para a construção de significados sobre o mundo com atividades de ensino a serem reconstruídas e rediscutidas na escola a partir de encontros com a leitura.

Linguagens - Revista de Letras, Artes e Comunicação ISSN 1981-9943 Blumenau, v. 11, n. 1, p. 324-339, jan./abr. 2017 
A leitura - e o gosto por ela - deveria ser a grande herança construída na escola. Professores e alunos, em conjunto, poderiam reorientar suas práticas para favorecer o processo de ensino-aprendizagem a partir da leitura. Se esse elo fosse efetivamente construído com os estudantes ao longo da vida escolar, a leitura estaria mais presente no cotidiano das pessoas ao invés de ser um formalismo para resolver questões de trabalho e/ou de atividades escolares.

A função social da escola deveria ser a de favorecer encontros com a leitura e não de frustrá-los. Ainda estão presentes nas escolas as experiências traumáticas das aulas de português cujo foco é a leitura e interpretação de textos, pautadas nas normas gramaticais de estudo. Isso é recorrente. Tais atividades expulsam nossos alunos da escola antes que eles possam completar sua formação. Se a escola fala e manda ler apenas uma língua que o aluno não vê significado, que ele não fala e não se vê representado nela, dificilmente será cativado pela leitura. Paulo Freire já destacava para a existência dos alunos que não se deixaram expulsar pelas atividades da escola. Esses apontamentos ainda devem ser considerados, sobretudo nas atividades de leitura. Propor atividades de leitura que não expulsem os alunos dessa prática ainda é uma grande tarefa a ser desenvolvida, discutida e problematizada na escola, pois o fato é que o gosto pela leitura não foi e ainda não é uma formação construída, em sua maioria, na escola. E precisamos nos preocupar com isso, não apenas para refletir sobre o problema, mas para evitar que as próximas gerações precisem passar por isso.

A leitura poderia ser compreendida enquanto uma atividade libertadora ${ }^{11}$ no sentido freireano do termo. A libertação, em Paulo Freire, tem um sentido coletivo. O sujeito não se liberta sozinho ou pelos seus próprios gostos, daí a necessidade de a escola intervir e mediar o processo de formação do sujeito pela leitura. Quando a escola silencia e/ou se isenta dessa responsabilidade social, ela trabalha em favor do discurso dominante, logo, do opressor. Se houver uma ressignificação para a leitura nas atividades da escola, essa prática social passaria a ser uma herança adquirida no processo de escolarização dos sujeitos e o próprio termo escolarização seria lido de forma saudosista, não com o cunho pejorativo a que muitas vezes está submetido e vinculado nas discussões teóricas.

Para Foucambert "desescolarizar a leitura significa que, tanto em relação às crianças quanto aos adultos, todas as instâncias educativas devem ter o cuidado de formar o leitor sob o ângulo da técnica e do manuseio do livro" (Grifos do autor. 1994, p. 16). Não basta apenas ter contato com o livro, é necessário torná-lo significante no processo de formação para que ele tenha outra relação de sentido que não a de lê-lo para realizar uma tarefa escolar. A escola tradicional vinculou o uso do livro a ter que, obrigatoriamente, cumprir uma tarefa. Não foi permitido 
sequer construir outro tipo de relação: lia-se na escola para responder o exercício, estudar a gramática, verificar se a pontuação está sendo respeitada na verbalização do texto ou se foi empregada corretamente na frase, entre outros. A leitura descuidada, prazerosa e/ou livre sempre foi vista como perda de tempo e meramente descompromissada com as atividades que se diziam de cunho escolar, por isso, nunca havia tempo para essa leitura-fruição ${ }^{12}$ durante as aulas, salvo quando já se tivesse cumprido toda a ordem do dia prevista na aula de português e ainda restasse/sobrasse tempo. Então, para que os alunos não ficassem ociosos, havia a obrigatoriedade de ler para que o tempo fosse preenchido, porque ficar na escola sem fazer qualquer atividade também não era e nem é permitido.

A escola tradicional sequenciou e normatizou o ensino de leitura e os graus para que o aluno avançasse em relação a ele. Vejamos um exemplo: há orientações de que a criança deva chegar ao $1^{\circ}$ ano sabendo algumas letras, sobretudo, as do nome. No $1^{\circ}$ ano espera-se que os alunos conheçam as letras, formem sílabas simples e leiam palavras com elas, bem como frases e textos pequenos. Além disso, também é importante saber representar o que falam, valendo-se do código escrito em construção. Posterior a este trabalho, esperta-se que o aluno, no ano seguinte ( $2^{\circ}$ ano), consiga ler palavras com sílabas mais complexas, textos mais extensos e possam escrever com mais facilidade o que pensam. Estas exigências são citadas apenas como referência ao trabalho de escolarização que a escola realiza, não devem ser lidas com a rigidez do que se espera que os alunos atinjam em cada série citada.

Certamente, os alunos conseguem perceber esses contextos dentro da escola: a sutil diferença entre leitura atividade artificializada e leitura práxis social de intervenção no mundo. "A ideia de desescolarização da leitura é, pois, a de formação permanente do leitor, a ser assumida por todas as instâncias educativas" (FOUCAMBERT, 1994, p. 17). A escola teria a função de mediar essa formação permanente estabelecendo articulações entre as variadas práticas sociais de uso da leitura, inscrevendo políticas de letramento escolar.

A escola, pautada no modelo tradicional de ensino de leitura, que foi vinculado à concepção gramatical de linguagem, organizou etapas a serem vencidas pelos estudantes para que eles sejam classificados como leitores. Essas atividades foram organizadas de forma seriada: primeiro se ensina as letras, depois as sílabas, as palavras, a frase... e assim sucessivamente. Ao passo que orienta, a escola também fiscaliza o conteúdo ensinado, valendo-se de avaliações periódicas. São essas insistentes cobranças por resultados rápidos que acabam artificializando o trabalho com a leitura. 
Há uma série de níveis previamente organizados a serem alcançados pelos alunos. Foucambert destaca que na escola "é preciso ligar a escrita ao que já é conhecido, aplicando-se um código que lhe é dado" e por quê?, porque "a escola prefere utilizar outros caminhos...": o caminho da sequenciação, seriação, categorização, hierarquização dos conhecimentos para avaliar quem consegue ter acesso ou não a ele, entre outras explicações e argumentos (1994, p. 7). "Na escola, prefere-se explorar a língua escrita sem apelar para a memória visual, centrando foco no domínio de um código de correspondência muito aproximativo; depois lamenta-se que as crianças não saibam ler e cometam erros de ortografia!" (FOUCAMBERT, 1994, p. 7).

Segundo Foucambert, seria muito mais indicado investir em práticas de leiturização ${ }^{13}$. Ao nível da sala de aula, investe-se em leiturização quando a escola evita as doze maneiras simples de tornar difícil a aprendizagem de leitura que serão apresentadas a seguir com base na discussão do autor. Se estes pontos forem tomados por referência, pode-se verificar que, historicamente, foi isso que a escola tradicional imprimiu ao ensino e que prejudicou o trabalho com a leitura. Para agravar o ensino e a aprendizagem de leitura, a escola deve se limitar a:

1. [Estabelecer] como meta o domínio precoce das regras de leitura. 2. Cuide bem para que fonética seja aprendida e utilizada. 3. Ensine as letras ou as palavras, uma a uma, certificando-se de que cada letra ou palavra foi assimilada antes de passar para a seguinte. 4. Defina como objetivo principal uma leitura palavra por palavra perfeita. 5. Não deixe as crianças adivinharem; pelo contrário exija que elas leiam com atenção. 6. Procure evitar de todas as maneiras que as crianças errem. 7. Dê um feed-back imediato. 8. Detecte e corrija os movimentos incorretos dos olhos. 9. Identifique os eventuais disléxicos e trate-os o mais cedo possível. 10. Esforce-se para que as crianças apreendam a importância da leitura e a gravidade do fracasso. 11. Aproveite as aulas de leitura para melhorar a ortografia e a expressão escrita; insista também em que os alunos falem a melhor língua possivel. 12. Se o método utilizado não lhe satisfazer, tente outro. Esteja sempre alerta para achar material novo e técnicas novas (FOUCAMBERT, 1994, p. 13).

Essas doze maneiras de tornar difícil o processo de aprendizagem da leitura foi executado com maestria pela escola tradicional. Caso se tome por significação de escola os professores e demais funcionários que a constitui em seu trabalho diário, principalmente o professor no contato direto com os alunos, pode-se dizer que a atividade docente foi orientada historicamente por princípios institucionais ${ }^{14}$ que imprimiram normativas escolares, usadas para classificar e policiar a aprendizagem da leitura dentro das salas de aulas. O argumento levantado aqui não quer culpabilizar, tampouco, criminalizar a ação docente, o objetivo principal está em demonstrar como a escola, valendo-se de regimentos para o sistema educacional, construiu e estabeleceu prerrogativas para se manter no poder e regular as atividades de ensino, medindo níveis de aprendizagem através da aprovação e/ou reprovação dos estudantes. 
Nessa perspectiva, lia-se para ter domínio do código escrito. Este sim, sempre foi o foco do ensino escolar. Lia-se para estudar a língua na sua estrutura; para ter conhecimento do bom uso do vernáculo; ler para ter contato com a estética textual de prestígio historicamente valorizada (por isso uns autores e não outros); lia-se para conhecer as regras de composição do escrito. Tudo a seu modo, operado a partir de uma perspectiva estruturalista, âmbito em que o normativismo justificava apenas a aprendizagem da linguagem de prestígio (norma culta). Dessa forma, podemos destacar que a escola cumpre muito bem o seu papel de instituição burguesa, criada pela própria burguesia para prolongar no tempo seus princípios, ideias e ideais.

Para reverter esse processo faz-se necessário tornar todas as atividades escolares - e não só a de leitura - ações heterogêneas de intervenção. Foucambert, conforme citado anteriormente, destaca que a leitura é presa de um corpo homogêneo na escola, ou seja, essa prática nada mais é que um processo repetitivo e sempre reiterado. É necessária uma mudança de perspectiva para que ler se torne uma ação consciente, uma prática social na escola. E não é pela mera verbalização do código escrito que isto será conquistado.

Construir ações heterogêneas significa constituir atos conscientes de intervenção desde a práxis docente, para que essa intervenção seja política, ideológica, histórica, concreta e efetiva (apontando caminhos), sobretudo, nas atividades que envolvem a leitura na escola. Entretanto, como consegui-las? A ideia é redimensionar as metodologias de ensino e concepções teóricas orientadoras, que nem precisam ser tão inovadoras para atingir bons resultados. O gênero debate pode ser utilizado como proposta para o trabalho com a leitura na sala de aula de forma mais consciente e crítica, por exemplo. O próximo tópico dispõe-se à discussão dessa proposta.

\section{O DEBATE COMO PROPOSIÇÃO PARA O TRABALHO COM A LEITURA ${ }^{15}$}

Em favor do debate na escola, há que inscrevê-lo alicerçado pela perspectiva dos gêneros discursivos a que Bakhtin se refere quando diz que o uso da língua se efetua em forma de enunciados (orais e escritos) e que cada esfera/campo da atividade humana "elabora seus tipos relativamente estáveis de enunciado, os quais denominamos de gêneros do discurso" (grifos do autor, BAKHTIN, 2011, p.262). Essa concepção faz-se preponderante para se refletir sobre $o$ debate enquanto ato consciente de constituição do sujeito a partir de atividades de leitura ${ }^{16}$.

No debate entram em ação as concepções sócio-históricas, ideológicas, políticas, sociais, relações de força e poder (instituídos) que os sujeitos trazem consigo do lugar em que falam, em que realizam os seus discursos e constituem seus enunciados. Rodrigues, pautada nas ideias 
de Bakhtin, destaca que "o enunciado não se repete, pois é um evento único (somente pode ser citado)" (2005, p.154); nesse sentido, o enunciado pode ser lido como um acontecimento ${ }^{17}$ discursivo em uma determinada atividade de interação verbal. É nesse sentido que se quer trabalhar com o gênero debate na sala de aula durante os processos de leiturização: para pôr em confronto discursos e ações no mundo a partir de perspectivas diferentes, que fomentem a controvérsia e a tomada de posição frente aos campos políticos, históricos, ideológicos e de poder.

Para uma escola que vislumbre o ensino de leitura orientando para os embates sociais para as lutas simbólicas e ideológicas entre grupos que agem no intuito de alcançar poder e hegemonia - ler o mundo, a palavramundo, pode significar a tomada de consciência na formação do sujeito. Os alunos se tornam mais atentos quanto ao papel que ocupam nessas relações assimétricas, reelaborando formas de intervenção - e a leitura consiste em um desses dispositivos de mudança e resistência. Nesse sentido, vale destacar que as respostas dos sujeitos diante de questões sociais podem contribuir para os processos de deslegitimação e desconstrução dos discursos dominantes. De acordo com Borges "quanto mais complexa a atividade de ler no âmbito social mais complexo vai se tornando o conceito de leitura", suas reverberações políticas e também seus significados na formação dos sujeitos (2012, p. 281).

Conforme citado anteriormente, o debate favorece o trabalho com a leitura, promovendo uma consciência política, ideológica, histórica, concreta e efetiva aos alunos. Nesse sentido, ao ter a necessidade de se posicionar dentro da discussão, o indivíduo é levado a refletir sobre o que defender, questionar, negar etc. Diante desse fato, cabe um posicionamento que é político, onde o sujeito reconhece os princípios que justificam e orientam sua opinião; que observe as ideologias implícitas no próprio discurso e no discurso dos outros; que seja capaz de identificar os nexos históricos e estabelecer relações profícuas que desestabilizem e denunciem o jogo de poder existente entre as ideias postas em discussão, a fim de elaborar um discurso que torne concreta e efetiva a sua leitura de mundo para intervir na sociedade.

Essa proposta se constitui como projeto de intervenção no mundo mediadas pela leitura na escola. Ela reverbera para além dos muros da escola, auxiliando na formação de sujeitos mais conscientes dos usos da leitura no contexto das relações sociais. Dessa forma, há de se esperar que da formação escolar será fruto o constructo crítico que empodera os sujeitos diante do mundo. A leitura como um processo em direção à, já que o debate sempre é uma leitura do mundo discutida em conjunto, nunca unânime e definitiva.

Analisado dessa maneira, o trabalho com o gênero debate desartificializa certas concepções de leitura ainda em vigor nas salas de aula e desfaz a política de policiamento que a escola sempre esteve arraigada. Desconstrói a perspectiva da resposta correta a que a escola se filiou 
historicamente. Ler-se-ia para constituir um projeto de dizer que intervisse sobre uma temática ou problema social e não para responder às perguntas que os livros trazem; também não se leria para empregar as regras gramaticais ao texto ou vice-versa, tampouco para verificar se os alunos estão verbalizando certo ou errado, se respeitam as regras das pausas, entonações etc.; ler-se-ia para construir e constituir mundos.

Se todas as leituras escolares tivessem sido realizadas com a finalidade de construir pensamentos ao invés de apenas reproduzi-los, copiá-los, sintetizá-los, resumi-los, resenhá-los, fichá- $\operatorname{los}^{18} \ldots$ a escola teria desempenhado um grande ato de/na formação de leitores e sua contribuição social seria maior. Contudo, apenas alguns dos que conseguiram não se deixar escolarizar ao longo dos anos estudando, hoje, empenham-se em problematizar certos contextos de ensino dessa instituição que, desde sua fundação, vem se propondo formar indivíduos para o convívio social mediante à leitura, mas que sempre limitou a policiar e julgar aptos ou inaptos sem avaliar seus próprios atos e estruturas durante muito tempo.

\section{CONSIDERAÇÕES FINAIS}

As últimas palavras estabelecem algumas relações a partir dos objetivos organizados no início deste artigo: conforme discutido, entender a leitura realizada nas instituições de ensino escolar apenas enquanto um nexo causal é incorrer numa estreita visão do problema. A tarefa ganha mais fôlego quando se investiga os modos que a escola se valeu e se organizou para fiscalizar o processo de ensino-aprendizagem de leitura em seus ambientes. Sobretudo quando se associou o ensino de leitura às concepções de linguagem que, historicamente, fundamentaram seu trabalho. Olhar para essa organização com o objetivo de refletir sobre os dispositivos de ensino é preponderante para aprofundar as discussões acerca das estruturas escolares e construir sentido sobre como elas ganham corpo para inspecionar saberes. Por isso, concluir que a escola se valeu e ainda se vale de uma organização policiadora das atividades de leitura em seus ambientes de ensino. Tal atitude reguladora põe em xeque os avanços quanto ao nível de proficiência leitora dos alunos, visto que tais atividades ainda circunscrevem aspectos gramaticais, pautados na linguagem escrita, historicamente encarados de forma soberana no trabalho com a leitura.

As atividades centralizadas no código e na expressiva cobrança pelo domínio da gramática têm consequências expressivas quanto à aprendizagem e a formação do gosto de ler, já que os alunos não se sentem integrados a tais atividades. Elas acontecem apenas como suporte para estudo do código escrito. Contudo, quando o estudo da leitura centra sua proposta em uma atividade cujo objetivo seja a constituição de uma consciência crítica frente a um problema social, 
pode-se alcançar resultados mais positivos, sobretudo, com o debate de ideias dentro da sala de aula. Daí a leitura passa a ser um processo de construção de conhecimentos. Nesse sentido, ler é mais que decifrar um código, é atribuir significações ao mundo e se posicionar diante dele.

\section{NOTAS}

1 Esta referência deve ser entendida com elo temporal de transição do Feudalismo para o Capitalismo em que "a 'revolucionária' burguesia exigiu que, juntamente com outros privilégios exclusivos da nobreza feudal, a educação fosse voltada para todos os homens passando a ser um direito desses, deixando de ser apenas privilégio de classe. Assim a educação moderna, historicamente deixou de ser um privilégio para se tornar um direito" (Grifos dos autores. SOUZA; FERREIRA; BARROS, 2009, p. 490).

2 Momento histórico ilustrado pelo seguinte acontecimento: "quando a burguesia revolucionária havia se firmado no poder como classe dominante e dirigente da sociedade, [instituindo] a educação como dever" [do Estado] (SOUZA; FERREIRA; BARROS, 2009, p. 490).

3 O sentido que se deseja construir com o uso deste termo está relacionado à função de desenvolver no indivíduo um grau de instrução para a faculdade de relacionar e construir conhecimentos a partir das linguagens em suas múltiplas manifestações, sejam elas, científicas, artísticas, entre outras, ao longo do tempo.

4 Esta concepção de trabalho estava condicionada, sobretudo à disciplina de Português, mas também servia de base para o ensino das outras.

5 Para mais informações, o texto "Português na escola: História de uma disciplina curricular", de Magda Soares (2002), apresenta os percursos históricos de escolarização do saber e constituição do ensino de Línguas em nosso país desde a época áurea do Brasil Colonial. Aos poucos, a autora ilustra a constituição do Português como disciplina escolar pautada, primeiramente, no ensino do vernáculo (constituído pelo ensino de suas regras e estruturas gramaticais) e, com o tempo, avançando com o uso do texto para exemplificar as regras do bem escrever. Nessa concepção histórica, a língua era entendida "como "sistema", prevalente até então no ensino da gramática, [somada à] concepção da língua como expressão estética, prevalente inicialmente no ensino da retórica e da poética e, posteriormente, no estudo de textos" mesmo depois na concepção da língua como comunicação (SOARES, 2002, p. 169). É a esta leitura que se refere quando se associa a perspectiva tradicional de uso do texto e ensino de leitura e produção textual na escola.

6 Vale-se do termo de Foucambert (1989, p. 3).

7 Britto (1997, p. 102-103) identifica seis problemas no ensino tradicional: 1) a indefinição quanto à finalidade do ato de ensinar (ensinar para quê?); 2) a valorização da norma culta e da escrita, bem como a insistência nas regras de exceção no ensino da norma, ao invés do privilégio da regularidade, com o consequente abandono das e o preconceito contra as formas de oralidade; 3 ) a descontextualização e a falta de sentido nas atividades de leitura e produção de texto; 4) a falta de consistência e de adequação à realidade da teoria gramatical subjacente às gramáticas escolares; 5) a falta de vínculo claro entre a metalinguagem e a prática efetiva de análise linguística, que se limita a exercícios mecânicos de identificação de fragmentos linguísticos; e, 6) a desconsideração das descobertas e elaborações da linguística contemporânea. Os detalhes sobre cada um desses apontamentos podem ser conferidos no livro do autor. Neste artigo somente o associamos às questões de como a escola tradicional os relaciona ao trabalho com a leitura.

8 Destarte que essa busca de informações tem muito mais a ver com uma atividade mecânica para atender às questões propostas nos tradicionais exercícios de interpretação, cujas respostas buscam-se na 
própria superfície dos textos, por isso, às vezes, são literalmente transcritas deles para resolver o que se pede, do que um ato reflexivo de construção de significados em relação ao texto lido.

9 Texto publicado em Obras Escolhidas, vol. II.

${ }^{10}$ Não vazio porque é vazio e destituído de tudo, mas vazio a partir de muitos destroços teóricos. Olhar para a escola hoje já significa olhar a partir de muitos lugares, entretanto, que lugar teórico vive na escola, subsidiando suas orientações de trabalho com a leitura e a língua(gem)? É absolutamente necessário saber o que resiste na escola e que chega até nós no presente para conhecê-la melhor. Assim, é provável que a práxis docente e a aula enquanto acontecimento sejam os objetos empíricos par excelence, para compreender a escola. Nessa perspectiva, a razão metodológica poderia se dar a contrapelo: 1) o que os dados nos mostram que é a escola? e não o que se tem feito costumeiramente chamando de pesquisa lendo a escola a partir de uma teoria previamente dada. Ir para a escola estudá-la com uma linha teórica definida talvez não permita que se enxergue a escola que se tem, pois muitos pesquisadores só encontram a escola que já levam consigo em seus constructos teóricos pré-concebidos. Urge a necessidade de se encontrar os corpos esgarçados das teorias no trabalho docente dentro da sala de aula para saber como eles operacionam e auxiliam na construção de saberes dos alunos.

${ }^{11}$ No sentido a que Paulo Freire se refere quando fala do processo de libertação do sujeito e sua constituição enquanto tal.

${ }^{12}$ Termo tomado por referência à abordagem que João Wanderley Geraldi faz no livro $O$ texto na sala de Aula, (2006).

${ }^{13}$ Termo adotado por Foucambert (1994, p. 20) para discorrer sobre as práticas sociais de uso da leitura enquanto processo de construção de significados que não se resumem somente ao ato de decifrar o código escrito, mas o de agir no mundo, valendo-se da leitura.

${ }^{14}$ Leia-se todos os regimentos escolares que funcionam como eixos que normatizam o que deve ser ensinado ou não pelas instituições de ensino. Neles estão os conteúdos a ensinar e o que deve ser feito para lograr êxito na educação dos alunos. Todos os textos que prescrevem as ações e atos escolares. Leis, diretrizes, projetos político-pedagógicos etc., devem ser relacionados aqui.

${ }^{15}$ A priori, esta proposta não deve ser lida como receita para o ensino e o trabalho com a leitura na escola, mas que seja uma possibilidade de trabalho e não deve se limitar a ela, contudo pode suscitar a releitura de outras metodologias já utilizadas pelos professores, como novas ferramentas para o ensino.

${ }^{16} \mathrm{O}$ sentido atribuído a leitura neste ponto do trabalho constitui-se formado não apenas de ler e atribuir sentido ao código escrito, mas de construir significados mais abrangentes a partir do texto e se posicionar enquanto sujeito.

${ }^{17}$ Enquanto ato particular, único e singular de uma interação verbal específica.

${ }^{18}$ Neste momento da discussão, cabe uma observação, a mim, estarrecedora: como parece infinita a lista de verbos inventados pela escola para policiar a leitura e colocá-la sob o jugo da norma! Somam-se a esses, muitos outros que carregamos associados a leitura deste ou daquele livro de determinado autor.

\section{REFERÊNCIAS}

BAKHTIN, Mikhail. Estética da criação verbal. São Paulo: Editora WMF Martins Fontes, 2011.

BENJAMIN, Walter. Passagens. Belo Horizonte: Editora UFMG; São Paulo: Imprensa Oficial do Estado de São Paulo, 2009.

Linguagens - Revista de Letras, Artes e Comunicação ISSN 1981-9943 Blumenau, v. 11, n. 1, p. 324-339, jan./abr. 2017 
. Obras Escolhidas. Vol. II. São Paulo: Editora Brasiliense, 2011.

Obras Escolhidas. Vol. III. São Paulo: Editora Brasiliense, 2011.

BRITTO, Luiz Percival Leme. A sombra do caos: ensino de língua x tradição gramatical. Campinas: Mercado de Letras, 1997.

BORGES, Simone Bueno. As múltiplas faces da formação em leitura. In FIGUEIREDO, Débora de Carvalho; BONINI, Adair; FURLANETTO, Maria Marta; MORITZ, Maria Ester Wollstein (Orgs.) Sociedade, cognição e linguagem: apresentações no IX CELSUL. Florianópolis: Editora Insular, 2012.

FREIRE, Paulo. A importância do ato de ler. São Paulo: Cortêz, 2011.

FOUCAMBERT, Jean. A leitura em questão. Porto Alegre: Artmed, 1994.

GERALDI, João Wanderley (Org.). O texto na sala de aula. São Paulo: Ática, 2006.

GOULEMOT, Jean Marie. Da leitura como produção de sentidos. In CHARTIER, Roger (Org.). Práticas de leitura. São Paulo: Estação Liberdade, 2001.

MARTÍN-BARBERO, Jesús; REY, Germán. Os exercícios do ver: Hegemonia audiovisual e ficção televisiva. São Paulo: Senac, 2001.

SOARES, Magda. Português na escola - história de uma disciplina escolar. In: BAGNO, Marcos (Org.). Linguística da norma. São Paulo: Loyola, 2002.

SOUZA, Paulo Rogério de; FERREIRA, Magda Maria De Marchi; BARROS, Marta Silene Ferreira. História da criação da escola pública como instrumento da formação da educação burguesa. IN. IX CONGRESSO NACIONAL DE EDUCAÇÃO - EDUCERE, IX. ENCONTRO SUL BRASILEIRO DE PSICOPEDAGOGIA, III , 2009, Curitiba. Anais eletônicos... Curitiba: PUCPR, 2009. Disponível em: < http://www.puc pr.br/eventos/educere/educere2009/anais/pdf/ 2475 1142.pdf>. Acesso em: 09 maio 2015. 